\title{
ESOTERISMO CONTEMPORÂNEO E TRAJETÓRIAS POLÍTICAS
}

\author{
L. Nicolás Guigou ${ }^{1}$ \\ Susana de Azevedo Araujo
}

Resumo: $\mathrm{O}$ artigo procura relacionar as diferentes aproximações, e as diferentes atitudes canônicas em relação às tradiçōes que compõem o esoterismo contemporâneo. $\mathrm{Na}$ particularinterpenetração entre esoterismo e polííca, tentamos nosaproximarao conjunto de significaçôes e práticas que podem ser compreendidas como "pós-políticas". Trabalhando sob re a candida tura "esô" pa ra vereador de Assis Aymone, indagamos sobre novasatitudes anticanônicas (ou formadoras de novos cânones) que permitem um livre fluxo entre visões holísticas e práticas discursivas e não discursivas no âmbito político.

Palavras-chaves: esoterismo, pós-política, cânone.

Keywords: esoterism, post-politics, canon.

\section{POLÍTICA E ESOTERISMO}

Um "Manifesto da Sensibilidade pela Paz", com o conhecido símbolo do ying e yang, abre a propaganda do candidato a vereador para Porto Alegre, Assis Aymone:

Paz...Paz...Paz

mais que a bandeira branca

mais que o armistício além do desarmamento

muito além da razão dos homens.

Paz: é a paz é a paz é a paz

A conhecida figura do homem de Leonardo da Vinci se distribui por toda a capa do panfleto. É a divinização da forma humana, mas não pela

${ }^{1}$ Doutorando, PPGAS, UFRGS, bolsista CNPq. Prof. da Universidade da República, Uruguai.

${ }^{2}$ Doutoranda, PPGAS, UFRGS, bolsista CAPES. 
exacerbação do humano por cima de todas as ordens, e sim pela duplicação de uma outra ordem nas divinas proporçôes de Vitrubio que Leonardo indaga nessa imagem.

Uma das tantas imagens que mostra a influência sobre o artista das "...ideas del neoplatonismo florentino, sobre todo a través del 'Corpus hermeticum', en la traducción de Marsilio Ficino” (Roob, 1997, p. 21).

Sem dúvida que Harold Bloom ficaria horrorizado de ver a divina figura humana de Leonardo embaixo de um título que anuncia: ASSIS AYMONE-VEREADOR-15666.

Como bem lembra Magnani (1999), o polêmico defensor do cânone ocidental teria criticado certa confusão no atual esoterismo “...em comparação com os contextos históricos do gnosticismo cristão, da cabala judaica e do sufismo muçulmano, com os quais, segundo o autor, aquelas crenças estão originariamen te relacionadas" (Magnani, 1999, p. 9).

Mas o esoterismo da contemporaneidade - pelo menos o fragmento que nos oferece Assis Aymone - não tem essas preocupações com o tempo da tradição. A temporalidade se espalha numa quantidade de pequenos textos significantes que anunciam como eixo central o "Holismo".

Uma letra bem pequena diz o sobrenome do candidato a prefeito (Mendes) e o número da lista. O partido de Assis Aymone é o Partido do Movimento Democrático Brasileiro (PMDB). Mas essa informação é liliputiana. Quase desaparece (esse 'quase' é muito impor tante) quando Assis Aymone tem que apresentar seu movimento. A prática discursiva que confirma esse "nós" vem de além e perpassa a política:

O movimento pela vida e pela paz nasceu de forma espontânea como resultado da reflexão e indignação de algumas pessoas, que pasmas ante a inércia do poder público perante o flagelo do ser humano e da natureza, começou a desenvolver ações diretas. Temos como pressuposto o Humanismo, o Holismo e o MeioAmbiente. Você certamente é um de nós, preocupado(a) com a preservação da vida,com o equilíbrioe a harmonia entreo ser humano, a sociedadee a natureza. Sabemosdos limitesde nossas açōes, por isso formamosum coletivo independente/ suprapartidário,com o intuito de ampliarmosnosso lequede ação na Câmara de Vereadores, órgão responsável pela elaboração das políticas públicas. Junte-se a nós. (Texto extraído do Programa de Campanha do candidato). 
Esse coletivo independente e suprapartidário possui uma larga lista de saberes, que mostram a pluralidade dessa visão holística baseada num olhar integrado do ser humano e da sociedade. Um olhar com um estilo que talvez poder-se-ia dizer pós-político, onde a política faz parte de uma transformação mais ampla e mais integrada e não o núcleo central, totalizador de práticas discursivas e não discursivas.

Os citados saberes direcionam as possibilidades destescaminhos de transformação,sem dúvida múltiplos:reike,yôga e yoga, florais,shiatsu,acupuntura, homeopatia, cromoterapia, fitoterapia, chakraterapia. neurolingüista, regressão, logoterapia, do in, cristais, feng shui, ecovilas, biodança, tai chi, astrologia, runas, cabala, tarô, I-CHING, numerologia, projeciologia, xamanismo, hare krishna, raj nij, hippies, humanismo, vegetarianismo, budismo, gnosis, antroposofia, espiritismo, filosofia védica, calendário maia, somaterapia, reflexologia, ecologia profunda, inteligência emocional.

Sim, Bloom teria entrado em desespero. Seu trabalho (não muito conhecido) sobre Gershom Scholem (Bloom, 1999) inscreve uma estratégia de leitura com sua tipologia de leitores. É importante destacar que esta postulação de leitores está inscrita no texto de Bloom. Olhando como se a textualidade fosse um palimpsesto, trata-se de uma mera referência, de uma escrita que ela mesma já se supõe.

O texto de Bloom sobre Scholem, um belo texto sobre a Cabala (um dos tantos itens que compóem o holismo de Assis Aymone) se refere às novas versōes desta tradição da seguinte maneira: "Los manuales populares sobre la Cábala no siempre son muy exactos en su contenido y tienden a estar peligrosamente ansiosos de mezclar la Cábala casi con cualquier otro entusiasmo actual, desde el sufismo hasta el hinduismo" (Bloom, 1999, p. 200).

Mas a tolerância com essas misturas místico-esotéricas não preocupa a um erudito como Bloom que conhece a história da Cabala e pode afirmar que, de fato, o diálogo entre a Cabala e outras correntes se encontra presente pelo menos desde a Renascença.

Seu objetivo, através de seu texto, são os leitores cultos que, como tais, podem ter acesso ao conhecimento da Cabala por meio da obra de Scholem. Assim "... los lectores cultos no necesitan, sin embargo, atenerse a esos manuales" (Bloom, 1999, p. 200). 


\section{APROXIMAÇÃO AOS SABERES SOTERRADOS}

Bloom se dirige aos leitores cultos, aqueles que podem aproximar-se das grandes tradições de uma forma canônica e erudita. Tudo isto está muito longe das preocupações de um coletivo independente e suprapartidário (embora se encontre dentro do $\mathrm{PMDB}$ ) que quer reintegrar à polis estes saberes soterrados. Trata-se acaso de uma cidadania "neo-esô" de acordo com a expressão de Magnani (1999)?

Vejamos. Esse grande saber holístico que direciona as atividades privadas e públicas (sobretudo políticas) de Assis Aymone, lembra a atividade mitopoética do clássico bricoleurlevistraussiano. Porém, nosso bricoleurnão trabalha comfragmentos de discursos e acontecimentos para produzir um sentido em si mesmo. Não é somente a "máquina classificatória" em ação que produz sentido per se.

Como fragmento do esoterismocontemporâneo não coloca suas ênfases numa leitura canônica da tradição, embora se refira a ela de forma constante. Mas não é a tradiçãode Bloom, que exige uma laboriosaexegese, a procura de uma trama que levará de um texto a outro. Uma leitura dir-se-ia desencantada, que consegue adentrar-se na tradição cabalista como objeto literário.

O exercício da hermenêutica do holismo político de Assis Aymone é pois heteróclito e produz seu sentido não unicamente no labor de bricoleur e sim na procura de um conjunto de saberes-possibilidades. A pluralidade valorizada que colabora com a renovação integral, holística, para um novo lugar da humanidade no universo. Mas por que o PMDB? Esta visão transformacional não estaria mais cômoda dentro de uma opção de esquerda, tipo uma esquerda "neo-esô"?

Assis Aymone foi do PT. Um grande desengano fê-lo desfiliar-se do partido:

No litoral eu descobri escondido numa chácara o famoso personagem cantado em letras, em livros, em músicas, o João Sem Terra, que participou do grupo dos 11 do Brizola, que era perseguido, percorreu toda a América Latina na questão agrária, insuflandoos camponeses, criando sindicatos. Eletava escondido juradode morte,na chácara, já velho,escondido em SantoAntônio da Patrulha, interior de Santo Antônio de Patrulha em 89. Eu conheci a filha dele, era 
professora em Tramandaí. Aí quando ela sentiu que podia confiar em alguém ela me abriu. Eu recuperei o João Sem Terra e trouxe ele aqui. Pensando que ele ia ser recebido com laudas, pelo menos o valor histórico do sujeito ser reconhecido. Ele foi trucidado,foi trucidado. O Movimento Sem Terra (MST) era aparelhado pelo Adão Preto e Silvino Reack na época, foi trucidado...

O sujeito já tava velho, não tinha grandes ambiçóes políticas. No mínimo que fosse recebido, que entendeu, sei eu, com honra, sei lá, que diabo de coisa, que fosse bemvindo,entende. Pela história do sujeito,ele foitrucidado, houve também questóes políticas intrínsecas, depois que me impediram de ver o JoãoSem Terra. Pegaram o JoãoSemTerra(...), esconderamo João SemTerra, quiseram fazer joguetes políticos internos. Olha, pra mim foi à gota d'água. Pra mim foi à gota d'água. Me desfiliei do PT, fiquei dois anos sem partido nenhum. (Aymone, 45 anos).

A decepção das práticas do PT leva Assis Aymone a procurar outro partido que não tenha um programa tão rígido nem uma estrutura partidária tão elaborada. Encontra no $\mathrm{PMDB}$ essa ausência de estrutura partidária e de programa. Um partido, segundo ele, diferente de todo o resto:

$\mathrm{O}$ PMDB na verdade ele não é um partido. $\mathrm{O}$ PMDB é um movimento, o PMDB é uma frente. Tem algumas lideranças do PMDB que acabam falando pelo partido e etc. O PMDB é um movimento, o PMDB é um partido inorgânico. $\mathrm{O} P M D B$ não tem uma estrutura partidária... então nesse sentido o PMDB é o partido mais aberto, neste exato momento deve tá saindo uns 100 do PMDB e deve tá entrando uns outros 100. Então ele é o partido mais aberto, ele é o partido mais plural. Qual é a ideologia do PMDB? Qual é o programa? Então, ele é mais plural, ele é mais múltiplo...”

É nesse fluxo, nessa porosidade, que o candidato a vereador encontra um espaço para difundir seu holismo. Sua percepção do PMDB como partido sem programa, sem ideologia, sem estrutura, não configura um elemento negativo. Pelo contrário, essas ausências falam da abertura, da pluralidade, da multiplicidade que Assis Aymone encontra no PMDB. Mas não são as mesmas características que o holismo deve ter?

De fato, fazendo uma avaliação da pluralidade que alimenta o holismo, o candidato do PMDB estabelece: 
Existe também, entre essas diversas práticas e técnicas e dentro de cada técnica, por exemplo, o yôga tem o yoga, se tu juntar os dois provavelmente vai dar uma discussão ferrenha. Agora tu imagina entre cada grupo tem alguns que fazem reike, por exemplo, que vêm no xamanismo, não gostam muito do xamanismo, porque o xamanismo trabalha com determinadas energias. Mas aí também existem várias orientaçōes, dentro do próprio xamanismo. Tem o xamanismo mais voltado para os índios da América Latina, outro mais para os celtas, para os asiáticos, etc. É um contexto muito grande, no momento que ganhar uma dimensão maior esse movimento, eles vão começar a eclodir. Agora, nós estamos nesta fase, nós estamos na fase de tentar dar um direcionamento, de tentarorganizar, de tentararticular,sob uma novaproposta.

A elaboração de um direcionamento para esta pluralidade inclusive contraditória (uma espécie de síntese holística) é um processo, um fluxo, que tem características "antiestruturais", como no caso da visão do PMDB. Mais que pensar em termos de homologia talvez fosse interessante colocar esse duplo percorrido por universos políticos e religiosos transformáveis. Assis Aymone se instala - pelo menos discursivamente - em situações político-religiosas porosas, onde a interpenetrabilidade é possível.

Mas, ao mesmo tempo, seu direcionamento político, sua prática discursiva deve manter uma coerência também com práticas não discursivas. Se a prática holística pode estar além do político (na medida em que este é só uma ferramenta), e inclusive procurar um partido "de fluxo" para conseguir espaços, também deve ser coerente em não utilizar modalidades políticas clássicas de busca e acumulação de votos.

Analisando os vários motivos de porque não foi eleito (o número 15666 teria tido algum efeito negativo) Assis Aymone diz o seguinte:

Essa minha campanha eu não fiz nada. Eu simplesmente fiz a proposta e atirei para o ar. O que eu fiz é que as pessoas que tavam comigo quase todas trabalhavam e contratei quatro moças, para distribuir os panfletos em alguns lugares. Essa foi a minha campanha, e fazendo umas visitas. Eu fazia danças circulares sagradas às quintas-feiras, participava de algumas reuniōes do Calendário Maia, participava de algumas reuniōes do grupo da Maria Luíza Benites, que é xamânica. E de uma série de outras reuniōes. 
Nessas reuniões Assis Aymone não se apresentava como candidato: “...eu não fazia questão, não fiz propaganda. Porque eu acho que a minha presença já significava alguma coisa. Isso explica o baixo número de votos. Porque eu não quis acionar todo o mecanismo operacional político que normalmente eu acionava. E acionava muito bem. Não quis...”

Esse "acionava" que remete a um passado político, a um modo de operar politicamente (portanto, conhecido) não é utilizado na campanha. Porque o fim não é unicamente a ocupação de lugares na arena pública.

Fazendo referência aos diferentes grupos que dão a base a sua proposta holística, Assis Aymone nos diz:

embora eu tenha elaborado essa proposta com esse eixo eu não quis e não aparelhei nenhum desses seguimentos. Entende, eu não pedi voto para nenhum deles (....) Apenas elaboreia propostae deixei na consciência de cada um. Claro que é ingenuidade política, ingenuidade política. Mas dentrode uma concepção que eu achei que tinha que ser, não posso forçar. Agora, talvez, como seja a primeira vez, eu tinha que ganhar a confiança desse pessoal, demonstrar que eu não estava fazendo uso político deles e das propostas deles, foi o que eu fiz. Fui sacrificado, eu poderia ter gastado mais dinheiro e ter feito 2000 votos, não, não era essa proposta. A proposta realmente era de divulgação.

\section{FORMAS DE POLÍTICA E ESOTERISMO NA CONTEMPORANEIDADE}

O holísmo de "fluxo" e integrador ao qual assistimos discursivamente, encontra, no olhar de Assis Aymone, seu lugar num partido político visualizado também como de "fluxo". Aí ele conseguiu difundir sua proposta holística, mas com uma dinâmica que não é política. Ele quase não fez difusão (pelo menos, em termos de propaganda profissionalizada), não "aparelhou" os diferentes grupos dos quais queria seus votos, nem se mostrou com demasiada ênfase como o candidato "do esoterismo".

A difusão quase intimista de uma proposta "alternativa” foi também alternativaem seu estilo de procurar votos, porque o importante (pelo menos nesta primeira etapa, como assinala) era conseguir a confiança dos diferen- 
tes segmentos que compóem o esoterismo porto-alegrense. Sua preocupação estava centrada na visibilização do holismo no âmbito político, mais do que ganhar um lugar como vereador.

\section{OLHARES NÃO CANÔNICOS}

O lugar da verdade e o lugar da verdade no discurso não é uma tarefa antropológica. Nesse sentido, o relevante do discurso de Assis Aymone está sim em sua aproximação não canônica (ao contrário de Bloom) às fontes das tradições. Essa aproximação é tambémanticanônica em seu engajamento com sua proposta política, no sentido que ele não utiliza o estilo da política (que, porém, conhece) para fazer política. Também é anticanônica no sentido de considerar que a porosidade de um partido (o PMDB) para sua proposta implica ausência de uma organização mais rígida, ideológica, autocentrada.

Embora ten ha fracassado em obter seu cargo de vereador, o posicionamento de Assis Aymone traz um insight interessante de uma das possibilidades da relação que pode se inaugurar entre a dimensão de crenças religiosas e políticas. Seu posicionamento está além e aquém da política: ele é pós-político, anticanônico.

Mas, também, poder-se-ia dizer que a posição deste singular candidato a vereador do $\mathrm{PMDB}$ estabelece novas possibilidades para o estabelecimento de um cânone diferente, tanto em relação à apropriação dos "saberes soterrados", quan to para práticas políticas que vão por outro viés do que as clássicas. Uma certa sensibilidade talvez não nova, mas que indica mais uma vez os múltiplos olhares de nosso mundo pós-político.

\section{REFERÊNCIAS}

BLOOM, Harold. Scholem. In: COHEN, Esther (Ed.) Cábala y desconstrucción. Barcelona: Azul-UNAM, 1999.

MAGNANI, José Guilherme C. Mysticaurbe.São Paulo: StudioNobel, 1999. ROOB, Alexander. Elmuseohermético.Alquimia\& mistica.Colonia:Taschen,1997. 